\title{
Effects of bupivacaine, levobupivacaine and ropi- vacaine on myocardial relaxation
}

\author{
[Les effets de la bupivacaïne, lévobupivacä̈ne et ropivacä̈ne sur la relaxation du \\ myocarde]
}

Jean-Stéphane David MD, ${ }^{*}$ Christian Ferreti MD, ${ }^{*}$ Julien Amour MD, $†$ Benoit Vivien MD, $†$ Olivier Eve MD, $\ddagger$ Paul Petit MD, ${ }^{*}$ Bruno Riou MD,$\dagger$ Pierre-Yves Gueugniaud MD*

Purpose: Ropivacaine and levobupivacaine were developed to reduce the risk of occasional toxicity reported with bupivacaine. While the effects of long-acting local anesthetics (LAAs) on myocardial contractility (inotropy) are well described, their effects on relaxation (lusitropy) remain largely unknown. The present study aimed to compare the effects of LAAs on rat myocardium.

Methods: Left ventricular papillary muscles of male Wistar rats were used to compare the inotropic and lusitropic responses of increasing concentrations of LAAs $\left(10^{-8}\right.$ to $\left.10^{-3} \mathrm{M}\right)$ under isometric and isotonic conditions. Data are mean \% (SD) of baseline value.

Results: Long-acting local anesthetics induced a significant impairment of relaxation in isotonic and isometric conditions. As compared to ropivacaine, bupivacaine and levobupivacaine induced greater negative lusitropic effects in isotony [at $10^{-3}$ $\mathrm{M}$, maximum unloaded shortening velocity $\left({ }_{\max } \mathrm{Vr}\right)=27 \pm \mathrm{II}$ vs $13 \pm 6$ and $8 \pm 5 \%]$ and isometry (at $10^{-3} \mathrm{M}$, time-to-halfrelaxation: $106 \pm 10$ vs $127 \pm 17$ and $133 \pm 17 \%$ ). When the comparison was made with equipotent concentrations, the negative lusitropic effects induced with levobupivacaine were significantly greater than those of bupivacaine and ropivacaine in isometric and isotonic conditions (at $10^{-3} \mathrm{M},{ }_{\text {max }} \mathrm{Vr}=7 \pm 4 \mathrm{vs} 13$ \pm 6 and $17 \pm 4 \%$ ). As previously described, LAAs also induced concentration-dependent negative inotropic effects that were greater for levobupivacaine compared to equivalent or equipotent concentrations of bupivacaine and ropivacaine.

Conclusions: Long-acting local anesthetics induce marked negative inotropic and lusitropic effects. Among LAAs, levobupivacaine exerts the greater depressant effects. Impairment of calcium handling and sarcoplasmic reticulum could explain the differential responses to local anesthetics.
CAN J ANESTH $2007 / 54: 3 /$ pp 208-217

Objectif : La ropivacaïne et la lévobupivacaïne ont été développées pour réduire le risque d'accidents sévères observés avec la bupivacaïne. Si les effets des anesthésiques locaux (LAAs) sur la contractilité myocardique (inotropie) sont bien décrits, les effets sur la relaxation (lusitropie) restent peu explorés. Cette étude a eu pour objectif de comparer les effets des LAAs chez le rat.

Méthode : Les effets de concentrations croissantes de LAAs $\left(10^{-8}\right.$ à $\left.10^{-3} \mathrm{M}\right)$ sur les réponses inotropes et lusitropes ont été comparés à l'aide d'un modèle de muscles papillaires. Les valeurs sont exprimées en \% de la valeur de base (moyenne $\pm E T$ ).

Résultats : Les LAAs ont entraîné une altération significative de la relaxation en isotonie comme en isométrie. En comparaison avec la ropivacaïne, la bupivacaïne et le lévobupivacaïne ont induit des effets lusitropes négatifs plus importants en isotonie [à 10-3 M, la vitesse de raccourcissement maximum sans résistance $(\max V r)=$ $27 \pm I I$ vs $13 \pm 6$ et $8 \pm 5 \%$ ] comme en isométrie (at $10^{-3} \mathrm{M}$, temps de demi-relaxation : $106 \pm 10$ vs $127 \pm 17$ et $133 \pm 17$ $\%)$. À des concentrations équipotentes, la lévobupivacaïne $a$ induit des effets lusitropes négatifs significativement plus importants que la bupivacaïne et la ropivacaine en isométrie comme en isotonie (à $10^{-3} \mathrm{M},{ }_{\text {max }} \mathrm{Vr}=7 \pm 4$ vs $13 \pm 6$ et $17 \pm 4 \%$ ). Les LAAs ont également induit des effets inotropes négatifs dose-dépendants qui ont été plus importants avec la lévobupivacaïne pour des concentrations équivalentes ou équipotentes.

Conclusions: Les LAAs ont induit des effets inotropes et lusitropes négatifs marqués. Parmi les LAAs, la lévobupivacaïne a eu les effets dépresseurs les plus marqués. Une altération de l'homéostasie calcique intracellulaire et du réticulum sarcoplasmique pourrait expliquer les différences d'effets entre LAAs.

From the Laboratoire d'Anesthésiologie, ${ }^{*}$ Université Claude Bernard et Départements d'Anesthésie-Réanimation, Hôpital Edouard Herriot et Centre Hospitalier Lyon-Sud, Hospices Civils de Lyon, Lyon; Laboratoire d'Anesthésiologie,† Université Pierre et Marie Curie et Département d'Anesthésie-Réanimation, Service d'Accueil des Urgences, CHU Pitié-Salpêtrière, Assistance Publique-Hôpitaux de Paris, Paris; Service d'Anesthésie-Réanimation, † Hôpital d'Instruction des Armées Desgenettes, Lyon, France.

Address correspondence to: Dr. Jean-Stéphane David, Département d'Anesthésie-Réanimation-SAMU, Hôpital Edouard Herriot, 3 place d'Arsonval, 69437 Lyon cedex 03, France. Phone: (33) 4721175 88; Fax: (33) 4721175 89; E-mail: js-david@univ-lyonl.fr

This study was supported solely by EA 1896 (Université Claude Bernard, Lyon) and EA 3975 (Université Pierre et Marie Curie, Paris) all in France. Dr. J Amour received a fellowship grant from the Fondation pour la Recherche Médicale (Paris, France).

Accepted for publication October 13, 2006.

Revision accepted December 1, 2006. 
I MPAIRED diastolic function is a major cause of heart failure in the general population and more than $40 \%$ of patients with heart failure have normal systolic function but compromised diastolic function. ${ }^{1}$ Concomitantly, diastolic dysfunction is increasingly recognized as a cause of hemodynamic instability in the perioperative setting. ${ }^{2}$ Diastolic dysfunction may be encountered in various clinical situations such as aging, hypertension, sepsis, diabetes or myocardial ischemia, and it may be also induced by anesthetic drugs including halogenated agents. ${ }^{3}$ Nevertheless, in cardiac-compromised populations, regional nerve blocks and/or epidural anesthesia are frequently used, either alone or as a complement to a general anesthesia. Because alteration of diastolic function can lead to cardiac failure, ${ }^{4,5}$ evaluating the effects of long-acting local anesthetics (LAAs) on myocardial relaxation may therefore be of particular interest.

Bupivacaine has been used as a LAA with success for more than 30 years. However, occasional but severe cardiac arrhythmias and central nervous system toxicity have been associated with this drug. ${ }^{6}$ Ropivacaine and levobupivacaine were developed as safer alternatives. Ropivacaine is the $S(-)$ isomer of the propyl analogue of mepivacaine and bupivacaine, whereas levobupivacaine is the $S(-)$ enantiomer of bupivacaine. Indeed, experimental and clinical data have demonstrated that these two agents may be less toxic than bupivacaine. ${ }^{6,7}$ Although the effects of LAA on myocardial contractility and cardiac conduction, as well as their mechanisms of action have been extensively documented, ${ }^{6,8-10}$ there are limited data reporting the effects of LAA on myocardial relaxation processes and diastolic function. ${ }^{11}$ Accordingly, this study was designed to make an in vitro comparison of the effects of bupivacaine, ropivacaine and levobupivacaine on myocardial relaxation in isolated rat papillary muscles.

\section{Methods}

We used adult male Wistar rats weighing 250-300 g. Care of the animals conformed to the recommendations of the Helsinki Declaration and the study was performed in accordance with the regulations of the official edict of the French Ministry of Agriculture.

\section{Experimental protocol}

Left ventricular papillary muscles were studied in a Krebs-Henseleit bicarbonate buffer solution (118 $\mathrm{mM} \mathrm{NaCl}, 4.7 \mathrm{mM} \mathrm{KCl}, 1.2 \mathrm{mM} \mathrm{MgSO}{ }_{4}$, $1.1 \mathrm{mM}$ $\mathrm{KH}_{2} \mathrm{PO}_{4}, 25 \mathrm{mM} \mathrm{NaHCO}{ }_{3}, 2.5 \mathrm{mM} \mathrm{CaCl}_{2}$ and 4.5 $\mathrm{mM}$ glucose) maintained at $29^{\circ} \mathrm{C}$ with a thermostatic water circulator (Polystat 5HP; Bioblock, Illkirch,
France) with continuous monitoring of the solution temperature using a temperature probe (Pt 100, Bioblock). Preparations were field stimulated at 0.2 $\mathrm{Hz}$ by two platinum electrodes with rectangular wave pulses lasting $5 \mathrm{msec}$ just above threshold. The bathing solution was bubbled with $95 \%$ oxygen and $5 \%$ carbon dioxide resulting in a $\mathrm{pH}$ of 7.4. After dissection, papillary muscles were allowed to recover their optimal mechanical performance during $60 \mathrm{~min}$ at the initial muscle length at the apex of the length-active isometric tension curve $\left(\mathrm{L}_{\max }\right)$. The extracellular calcium concentration $\left(\left[\mathrm{Ca}^{2+}\right]_{\mathrm{o}}\right)$ was decreased from 2.5 to 1 or $0.5 \mathrm{mM}$ to facilitate observation of a potential positive inotropic effect because rat myocardial contractility is nearly maximum at $2.5 \mathrm{mM} .{ }^{12}$

Inotropic and lusitropic responses of escalating concentrations $\left(10^{-8}\right.$ to $10^{-3} \mathrm{M}, n=8$ in each group) of levobupivacaine $0.5 \%$ (Chirocaine ${ }^{\circledR}$, Abbott, Belgium), racemic bupivacaine HCL 0.5\% (Bupivacaine ${ }^{\circledR}$, Aguettant, Lyon, France) and ropivacaine HCL 10\% (Naropene ${ }^{\circledR}$, Astra-Zeneca, Nanterre, France) were determined at a $\left[\mathrm{Ca}^{2+}\right]_{\mathrm{o}}$ of $1 \mathrm{mM}$. As suggested by Lyons et al. and Schug et Rosenberg, we used concentrations according to molarity and not clinical concentrations $\left(\mu \mathrm{g} \cdot \mathrm{mL}^{-1}\right){ }^{13,14}$ The inotropic and lusitropic responses were recorded ten minutes after each dose was added to the bathing solution. We also made comparisons using equipotent doses of ropivacaine and levobupivacaine with a potency ratio of 0.62 (ropivacaine/bupivacaine) and 0.90 (levobupivacaine/bupivacaine)..$^{15-17}$

In order to determine the mechanism by which LAAs may impair the contractile process, we studied the effects of LAAs at $10^{-4} \mathrm{M}$ (concentration that produces nerve block) on contractile responses to the following experimental conditions: increased $\left[\mathrm{Ca}^{2+}\right]_{\mathrm{o}}$ concentration, force-frequency relationship (FFR) and postrest potentiation. First, the effect on inotropic responses of increased $\left[\mathrm{Ca}^{2+}\right]_{\mathrm{o}}$ ( 0.5 to $1 \mathrm{mM}$ by step of $0.1 \mathrm{mM}$, contact time of $10 \mathrm{~min}$ ) was studied in the presence of LAAs ( $n=6$ in each group) to test their effects on calcium homeostasis. ${ }^{18}$ Second, we determined the effects of LAAs ( $n=6$ in each group) on FFR to test their effects on intracellular calcium handling and excitation-contraction coupling. ${ }^{19,20}$ Forcefrequency relationship was determined at a $\left[\mathrm{Ca}^{2+}\right]_{\mathrm{o}}$ of $\mathrm{l} \mathrm{mM}$ to minimize the phenomenon of calcium overload. ${ }^{21}$ The frequency of stimulation was increased from $0.1 \mathrm{~Hz}$ to $5 \mathrm{~Hz}(0.1,0.2,0.5,1,2,3,4$ and 5 $\mathrm{Hz})$ and active force (AF) was recorded. Third, the effects of LAAs ( $n=6$ in each group) were studied on postrest potentiation to provide insights into storage and release (SR) functions $\left(\mathrm{Ca}^{2+} \mathrm{SR}\right.$ capacity) in 
a biochemically intact preparation. ${ }^{12,20}$ The maximal isometric $\mathrm{AF}$ during postrest potentiation was studied after a one-minute rest duration, and at a $\left[\mathrm{Ca}^{2+}\right]_{\mathrm{o}}$ of $0.5 \mathrm{mM}$ because its study is more sensitive at a low $\left[\mathrm{Ca}^{2+}\right]_{0}$. During rest in the rat myocardium, SR accumulates calcium above and beyond that accumulated with regular stimulation and the first beat after the rest interval (Bl) is more forceful than the last beat before the rest interval (B0).22

Throughout the study we ensured that the highest concentration of local anesthetics (i.e., $10^{-3} \mathrm{M}$ ) did not significantly modify the concentration of ions such as ionized calcium: $1.01 \pm 0.05 \mathrm{mmol} \cdot \mathrm{L}^{-1}$ for bupivacaine, $1.02 \pm 0.01 \mathrm{mmol} \cdot \mathrm{L}^{-1}$ for levobupivacaine, $1.05 \pm 0.01 \mathrm{mmol} \cdot \mathrm{L}^{-1}$ for ropivacaine and $1.03 \pm 0.00$ $\mathrm{mmol} \cdot \mathrm{L}^{-1}$ in the control group by directly measuring its concentration (Modular P900; Roche Diagnostics, Meylan, France).

\section{Electromagnetic lever system and recording}

The electromagnetic lever system has been previously described. ${ }^{12}$ Briefly, the load applied to the muscle was determined using a servomechanism-controlled current through the coil of an electromagnet. Muscular shortening induced a displacement of the lever that modulated the light intensity of a photoelectric transducer. All analyses were made from digital records of force and length obtained using a computer, as previously described. ${ }^{22}$

\section{Mechanical parameters}

Conventional mechanical variables at $\mathrm{L}_{\max }$ were calculated from three twitches. The first twitch was isotonic and was loaded with the preload corresponding to $\mathrm{L}_{\max }$. The second twitch was abruptly clamped to zero-load just after the electrical stimulus with critical damping to slow the first and rapid shortening overshoot resulting from the recoil of series-passive elastic components. The third twitch was fully isometric at $\mathrm{L}_{\max }$. We determined the maximum unloaded shortening velocity $\left(\mathrm{V}_{\max }\right)$ using the zero-load technique, the maximum shortening $\left({ }_{\max } \mathrm{Vc}\right)$ and lengthening $\left({ }_{\max } \mathrm{Vr}\right)$ velocities and the time-to-peak-shortening of the twitch with preload only. Maximum isometric AF normalized per cross-sectional area, the peaks of the positive $\left(+\mathrm{dF} . \mathrm{dt}^{-1}\right)$ and the negative $\left(-\mathrm{dF} . \mathrm{dt}^{-1}\right)$ force derivatives at $\mathrm{L}_{\max }$ normalized per cross-sectional area, time-to-peak-force and the time to half-relaxation (THR) were determined from the isometric twitch.

Because changes in the contraction phase induce coordinated changes in the relaxation phase, indices of contraction-relaxation coupling have been developed to study lusitropy. ${ }^{23}$ The $\mathrm{Rl}$ coefficient $={ }_{\max } \mathrm{Vc} /{ }_{\text {max }} \mathrm{Vr}$ was used to study the coupling between contraction and relaxation under low load and thus lusitropy in a manner that is independent of inotropic changes. $\mathrm{R} 1$ tests SR uptake function. ${ }^{22,23}$ The R2 coefficient $=\left(+\mathrm{dF} \cdot \mathrm{dt}^{-1} /-\mathrm{dF} \cdot \mathrm{dt}^{-1}\right)$ studied the coupling between contraction and relaxation under high load and thus lusitropy in a manner that is less dependent on inotropic changes. ${ }^{22}$ When the muscle contracts isometrically, sarcomeres shorten very little. ${ }^{24}$ Because of the higher sensitivity of myofilament for calcium, the time course of relaxation is determined by calcium unbinding from troponin $\mathrm{C}$ rather than by calcium sequestration by the sarcoplasmic reticulum. ${ }^{25}$ Thus $\mathrm{R} 2$ reflects myofilament calcium sensitivity. ${ }^{23} \mathrm{R} 2$ is less modified by major inotropic changes induced by decreasing $\left[\mathrm{Ca}^{2+}\right]_{\mathrm{o}}$ than $+\mathrm{dF} \cdot \mathrm{dt}^{-1}$ and $-\mathrm{dF} \cdot \mathrm{dt}^{-1}$. Because $+\mathrm{dF} \cdot \mathrm{dt}^{-1}$ is depressed more than $-\mathrm{dF} \cdot \mathrm{dt}^{-1}$, the resulting decrease in R2 reflects a positive lusitropic effect. The slight decrease in $\mathrm{R} 2$, as $\left[\mathrm{Ca}^{2+}\right]_{\mathrm{o}}$ is decreased, is consistent with the fact that calcium per se modulates myofilament calcium sensitivity, according to the cooperativity concept. ${ }^{26,27}$

At the end of the study, the muscle cross-sectional area was calculated from the length and weight of papillary muscle, assuming a density of $l$.

\section{Statistical analysis}

Data are expressed as mean \pm SD and normality of their distribution was tested with the Shapiro-Wilk or Kolmogorov-Smirnov tests. However, because there are important differences in baseline values from one muscle to another, inotropic responses were expressed as a percentage of baseline values (i.e., after exposure to local anesthetics), as previously reported..$^{18,28}$ Comparison of two means was performed using the Student's $t$ test. Comparison of several means was performed using analysis of variance and the Newman-Keuls test. Baseline values between groups were compared using analysis of variance. All probability values were two-tailed and a $P$ value $<0.05$ was required to reject the null hypothesis. Statistical analysis was performed with NCSS 6.0 software (Statistical Solutions Ltd., Cork, Ireland).

\section{Results}

Eighty-three left ventricular papillary muscles were studied. The mean $\mathrm{L}_{\max }$ was $6.5 \pm 1.7 \mathrm{~mm}$, the mean cross-sectional area was $0.48 \pm 0.17 \mathrm{~mm}^{2}$ and the mean ratio of resting force to total force was $0.12 \pm$ 0.03 . Baseline values observed at a $\left[\mathrm{Ca}^{2+}\right]_{0}$ of $2.5,1$ and $0.5 \mathrm{mM}$ are shown in Table I. A decrease in contractility was observed as $\left[\mathrm{Ca}^{2+}\right]_{\mathrm{o}}$ was decreased from 2.5 to $\mathrm{l}$ or $0.5 \mathrm{mM}$. The decreases in $\mathrm{V}_{\max }(85 \pm 9 \%$ of 
TABLE I Baseline mechanical variables of papillary muscles at a $\left[\mathrm{Ca}^{2+}\right]_{\mathrm{o}}$ of $2.5 \mathrm{mM}, 1 \mathrm{mM}$ and $0.5 \mathrm{mM}$

\begin{tabular}{|c|c|c|c|}
\hline Variables & $\begin{array}{c}C a 2.5 \mathrm{mM} \\
(n=83)\end{array}$ & $\begin{array}{c}C a 1 m M \\
(n=53)\end{array}$ & $\begin{array}{c}C a 0.5 \mathrm{mM} \\
\quad(n=30)\end{array}$ \\
\hline \multicolumn{4}{|l|}{ Contraction } \\
\hline $\mathrm{V}_{\max }\left(\mathrm{L}_{\max } \cdot \sec ^{-1}\right)$ & $3.49 \pm 0.54$ & $2.67 \pm 0.75$ & $1.99 \pm 0.33$ \\
\hline${ }_{\max } V_{c}\left(L_{\max } \cdot \sec ^{-1}\right)$ & $2.41 \pm 0.40$ & $1.99 \pm 0.43$ & $1.10 \pm 0.28$ \\
\hline TPS (msec) & $184 \pm 14$ & $173 \pm 12$ & $170 \pm 17$ \\
\hline $\mathrm{AF}\left(\mathrm{mN} \cdot \mathrm{mm}^{-2}\right)$ & $120 \pm 57$ & $79 \pm 43$ & $51 \pm 23$ \\
\hline$+\mathrm{dF} \cdot \mathrm{dt}^{-1}\left(\mathrm{mN} \cdot \mathrm{mm}^{-2} \cdot \mathrm{sec}^{-1}\right)$ & $1462 \pm 809$ & $1133 \pm 579$ & $562 \pm 284$ \\
\hline TPF (msec) & $165 \pm 14$ & $158 \pm 15$ & $160 \pm 18$ \\
\hline \multicolumn{4}{|l|}{ Relaxation } \\
\hline${ }_{\max } \operatorname{Vr}\left(\mathrm{L}_{\max } \cdot \sec ^{-1}\right)$ & $3.72 \pm 0.78$ & $3.06 \pm 0.80$ & $1.77 \pm 0.56$ \\
\hline$-\mathrm{dF} \cdot \mathrm{dt}^{-1}\left(\mathrm{mN} \cdot \mathrm{mm}^{-2} \cdot \mathrm{sec}^{-1}\right)$ & $592 \pm 234$ & $532 \pm 257$ & $308 \pm 152$ \\
\hline THR & $320 \pm 41$ & $281 \pm 31$ & $270 \pm 34$ \\
\hline \multicolumn{4}{|c|}{ Contraction-relaxation coupling } \\
\hline $\mathrm{Rl}$, low loads & $0.67 \pm 0.11$ & $0.67 \pm 0.14$ & $0.66 \pm 0.17$ \\
\hline $\mathrm{R} 2$, high loads & $2.59 \pm 0.72$ & $2.01 \pm 0.49$ & $1.85 \pm 0.31$ \\
\hline
\end{tabular}

Data are mean $\pm S D . V_{\max }=$ maximum unloaded shortening velocity; ${ }_{\max } \mathrm{Vc}=$ maximum shortening velocity; ${ }_{\max } \mathrm{Vr}=$ maximum lengthening velocity; $\mathrm{AF}=$ isometric active force normalized per cross-sectional area; $+\mathrm{dF} \cdot \mathrm{dt}^{-1}=$ peak of the positive force derivative; $-\mathrm{dF} \cdot \mathrm{dt} t^{-1}=\mathrm{peak}$ of the negative force derivative; $\mathrm{Rl}=$ ratio of maximum shortening velocity $\left({ }_{\max } \mathrm{Vc}\right)$ to maximum lengthening velocity $\left({ }_{\max } \mathrm{Vr}\right) ; \mathrm{R} 2=\mathrm{ratio}$ of the peak of the positive force derivative $\left(+\mathrm{dF} \cdot \mathrm{dt}^{-1}\right)$ to the peak of the negative force derivative $\left(-\mathrm{dF} \cdot \mathrm{dt}^{-1}\right)$; TPS = time to peak shortening; $\mathrm{TPF}=$ time to peak force.
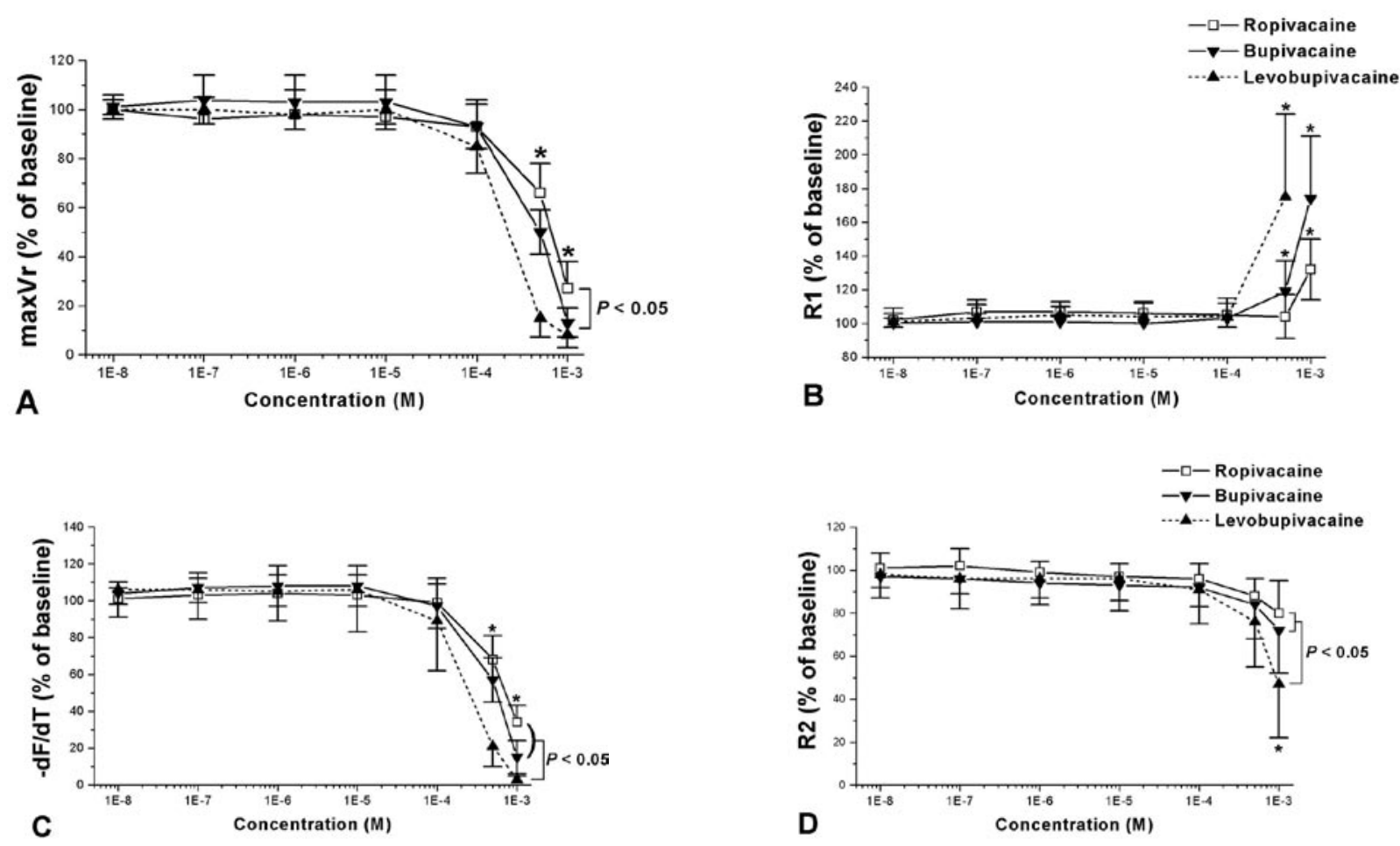

FIGURE 1 Comparison of the lusitropic effects of ropivacaine (R), bupivacaine (B) and levobupivacaine (L) under isotonic (panel A: ${ }_{\max } \mathrm{Vr}=$ maximum lengthening velocity, panel $\mathrm{B}: \mathrm{Rl}$ = ratio of maximum shortening to lengthening velocities) and isometric conditions (panel $\mathrm{C}$ : $\mathrm{R} 2=-\mathrm{dF} \cdot \mathrm{dt}^{-1}$ : negative peak force derivative, panel $\mathrm{D}$ : ratio of the positive to negative peak force derivatives) at a calcium concentration of $1 \mathrm{mM}$. The value observed for Rl with levobupivacaine at $10^{-3} \mathrm{M}$ was not shown because of the high degree of myocardial failure (Figure 3$)$. Values are mean $\%$ of baseline \pm SD $(n=8$ in each group). $P$ values refer to differences between groups $\left({ }_{\max } \mathrm{Vr}\right.$ and $-\mathrm{dF} / \mathrm{dT}=\mathrm{R}$ and $\mathrm{B} v s \mathrm{~L} ; \mathrm{R} 2=\mathrm{R} v s \mathrm{~B}$ and $\left.\mathrm{L}\right)$. ${ }^{*} P<0.05 v s$ baseline values. 

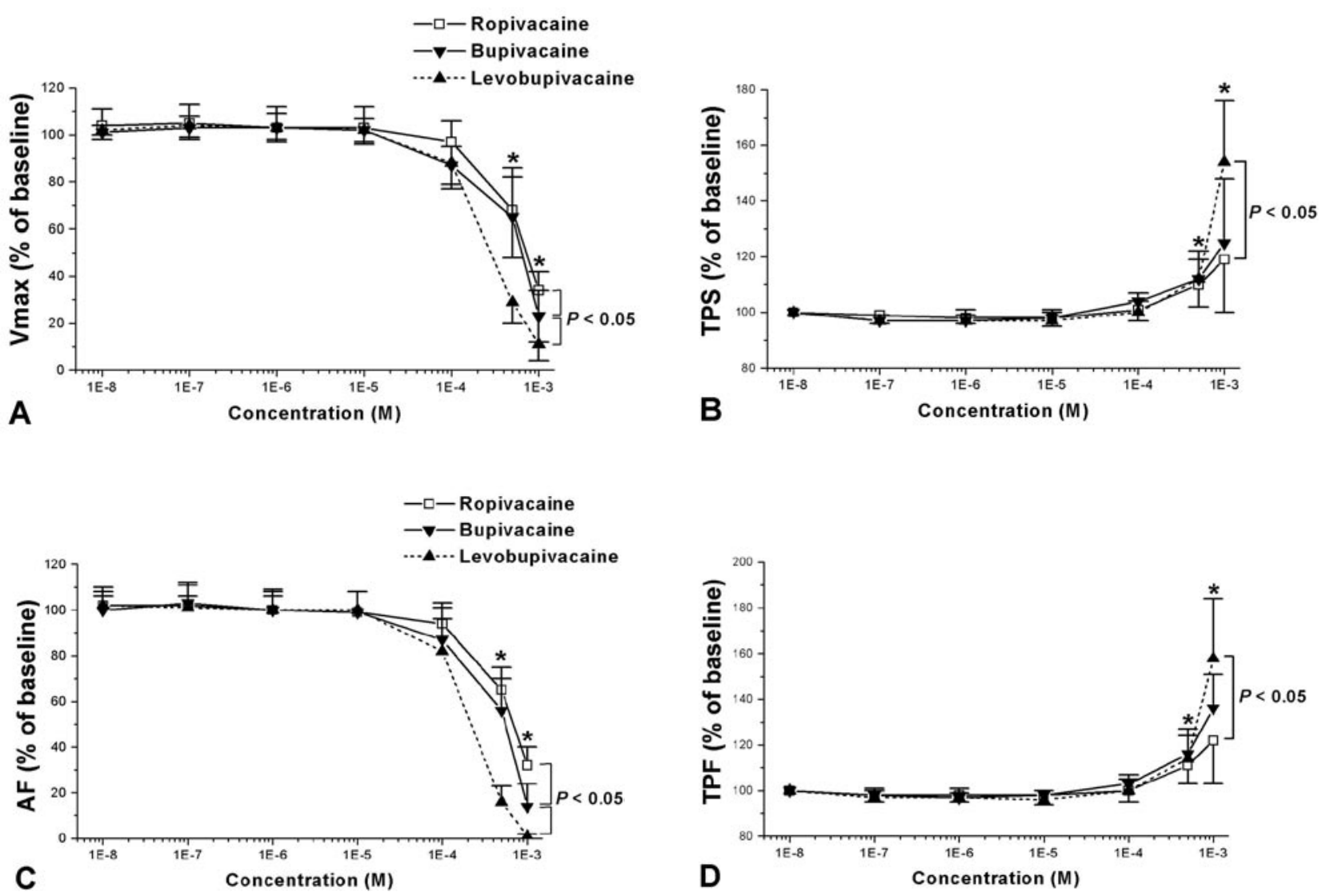

FIGURE 2 Comparison of the inotropic effects of ropivacaine (R), bupivacaine (B) and levobupivacaine (L) under isotonic (panel A: $\mathrm{V}_{\max }=$ maximum unloaded shortening velocity, panel B: TPS = time-to-peak-shortening) and isometric conditions (panel C: $\mathrm{AF}=$ active force, panel $\mathrm{D}: \mathrm{TPF}=$ time-to-peak-force) at a calcium concentration of $1 \mathrm{mM}$. Values are mean $\%$ of baseline $\pm \mathrm{SD}\left(n=8\right.$ in each group). $P$ values refer to between group differences $\left(\mathrm{V}_{\max }\right.$ and $\mathrm{AF}=\mathrm{R}$ vs $\mathrm{B} s \mathrm{~L}$; TPS and TPF $=\mathrm{R}$ vs $\mathrm{L}) .{ }^{*} P<0.05$ vs baseline values.

baseline at $\mathrm{a}\left[\mathrm{Ca}^{2+}\right]_{\mathrm{o}}$ of $1 \mathrm{mM}$ and $60 \pm 8 \%$ of baseline at a $\left[\mathrm{Ca}^{2+}\right]_{0}$ of $\left.0.5 \mathrm{mM}\right)$ and $\mathrm{AF}(77 \pm 12 \%$ of baseline at a $\left[\mathrm{Ca}^{2+}\right]_{\mathrm{o}}$ of $1 \mathrm{mM}$ and $44 \pm 11 \%$ of baseline at a $\left[\mathrm{Ca}^{2+}\right]_{\mathrm{o}}$ of $0.5 \mathrm{mM}$ ) were consistent with those previously reported. ${ }^{12}$

\section{Effects on myocardial relaxation}

Long-acting local anesthetic agents induced under low load ( $\mathrm{Rl}$ and ${ }_{\max } \mathrm{Vr}$ ) impairment of relaxation, but only at concentrations $\geq 5 \cdot 10^{-4} \mathrm{M}$ (Figure 1). This negative effect on isotonic relaxation was greater with bupivacaine and levobupivacaine than with ropivacaine. However, when the comparison was made with equipotent concentrations, levobupivacaine $(7 \pm 4 \%$ of baseline value, at $10^{-3} \mathrm{M}$ ) induced a greater negative effect on isotonic relaxation $\left({ }_{\max } \mathrm{Vr}\right)$ than ropivacaine $(17 \pm 4 \%)$ and bupivacaine $(13 \pm 6 \%)$.
Under high load (THR, -dF.dt $t^{-1}$ and R2), LAAs induced a significant decrease of $-\mathrm{dF} \cdot \mathrm{dt}^{-1}$ (Figure 1) while levobupivacaine and bupivacaine, but not ropivacaine, significantly increased THR (at $10^{-3}$ M, levobupivacaine: $129 \pm 14 \%$, bupivacaine: $119 \pm$ $9 \%$ vs ropivacaine: $106 \pm 10 \%$ of baseline value) and decreased R2 (Figure 1). However, because a decrease in AF per se induces a decrease in R2 (i.e., a decrease of myofilament calcium sensitivity), ${ }^{22}$ we compared the change in $\mathrm{R} 2$ corresponding to $10^{-4} \mathrm{M}$ of bupivacaine and levobupivacaine and $5 \cdot 10^{-4} \mathrm{M}$ of ropivacaine to that induced by lowering $\left[\mathrm{Ca}^{2+}\right]_{0}$ in order to obtain the same decrease in AF. We then observed that the decrease of R2 for levobupivacaine, bupivacaine and ropivacaine was smaller than that observed by lowering $\left[\mathrm{Ca}^{2+}\right]_{0}$ (respectively $91 \pm 16,92 \pm 9$ and $88 \pm$ 8 vs $71 \pm 10 \%$ of baseline, $P<0.05$ vs control). As 
TABLE II Effects of long-acting local anesthetics on postrest potentiation

\begin{tabular}{lll}
\hline & Baseline & Ropivacaine $10^{-4} M$ \\
\hline $\mathrm{BO}\left(\mathrm{mN} \cdot \mathrm{mm}^{-2}\right)$ & $35 \pm 15$ & $26 \pm 18$ \\
$\mathrm{~B} 1\left(\mathrm{mN} \cdot \mathrm{mm}^{-2}\right)$ & $59 \pm 28$ & $41 \pm 25$ \\
$\mathrm{~B} 1 / \mathrm{B} 0$ & $1.7 \pm 0.1$ & $1.7 \pm 0.2$ \\
& Baseline & Bupivacaine $10^{-4} M$ \\
$\mathrm{BO}\left(\mathrm{mN} \cdot \mathrm{mm}^{-2}\right)$ & $64 \pm 23$ & $55 \pm 23^{*}$ \\
$\mathrm{~B} 1\left(\mathrm{mN} \cdot \mathrm{mm}^{-2}\right)$ & $108 \pm 38$ & $95 \pm 36^{*}$ \\
$\mathrm{~B} 1 / \mathrm{B} 0$ & $1.7 \pm 0.2$ & $1.7 \pm 0.2$ \\
& Baseline & Levobupivacaine $10^{-4} M$ \\
$\mathrm{BO}\left(\mathrm{mN} \cdot \mathrm{mm}^{-2}\right)$ & $52 \pm 16$ & $34 \pm 8^{*}$ \\
$\mathrm{~B} 1\left(\mathrm{mN} \cdot \mathrm{mm}^{-2}\right)$ & $80 \pm 16$ & $64 \pm 16^{*}$ \\
$\mathrm{~B} 1 / \mathrm{B} 0$ & $1.6 \pm 0.3$ & $1.9 \pm 0.3^{*}$ \\
\hline $\mathrm{Bl}$
\end{tabular}

$\mathrm{Bl}$ is the first isometric contraction after rest, and $\mathrm{B} 0$ is the last isometric contraction before rest. Data are mean $\pm S D .(n=6)$. * $P$ $<0.05$ (Student $t$ test) $v s$ control values at a $\left[\mathrm{Ca}^{2+}\right]_{\mathrm{o}}$ of $0.5 \mathrm{mM}$.

previously observed in isotony, when the comparison was made with equipotent concentrations, levobupivacaine still had a greater negative effect on isometric relaxation. At $10^{-3} \mathrm{M}$, - $\mathrm{dF} \cdot \mathrm{dt}^{-1}$ was $21 \pm 6 \%$ (ropivacaine) and $15 \pm 9 \%$ (bupivacaine) as compared to $3 \pm$ $2 \%$ of baseline value for levobupivacaine $(P<0.05$ vs bupivacaine and ropivacaine).

\section{Effects on myocardial contractility}

Long-acting local anesthetics induced significant negative inotropic effect and slowing of contraction, both under isotonic and isometric conditions (Figure 2).
Levobupivacaine had greater myocardial depressant myocardial effects than ropivacaine and bupivacaine, whether the comparison was made with equivalent or equipotent concentrations. For example, with equipotent concentration of $10^{-3} \mathrm{M}$ of bupivacaine, $\mathrm{AF}$ (\% of baseline value) was $1 \pm 1 \%$ for levobupivacaine as compared to $14 \pm 10 \%$ for bupivacaine $(P<0.05$ vs levobupivacaine) and $21 \pm 7 \%$ for ropivacaine $(P<$ 0.05 vs bupivacaine and levobupivacaine).

\section{Mechanism of action}

Postrest potentiation was not significantly modified by ropivacaine and bupivacaine but was significantly increased by levobupivacaine (Table II). Increasing $\left[\mathrm{Ca}^{2+}\right]_{0}$ from 0.5 to $1 \mathrm{mM}$ resulted in a significant positive inotropic effect, in isotonic and isometric conditions that was significantly diminished in the levobupivacaine and bupivacaine groups (Figure 3).

When frequency was decreased from 0.2 (baseline frequency) to $0.1 \mathrm{~Hz}$, a significant positive inotropic effect was observed in all except the levobupivacaine group (Figure 4). Active force was $114 \pm 7$ (control), $110 \pm 6$ (ropivacaine) and $116 \pm 16$ (bupivacaine) ps $105 \pm 11 \%$ of baseline (levobupivacaine). Increasing frequency from 0.1 to $5 \mathrm{~Hz}$ resulted in a negative FFR that was significantly impaired by local anesthetics (Figure 4). At the end of the experiment, we verified that when frequency was set back to $0.2 \mathrm{~Hz}$, all muscles had returned to a value that was not significantly different from baseline values $(95 \pm 24,96$ \pm 10 and $101 \pm 27 \%$ of baseline value, respectively for ropivacaine, levobupivacaine and bupivacaine).
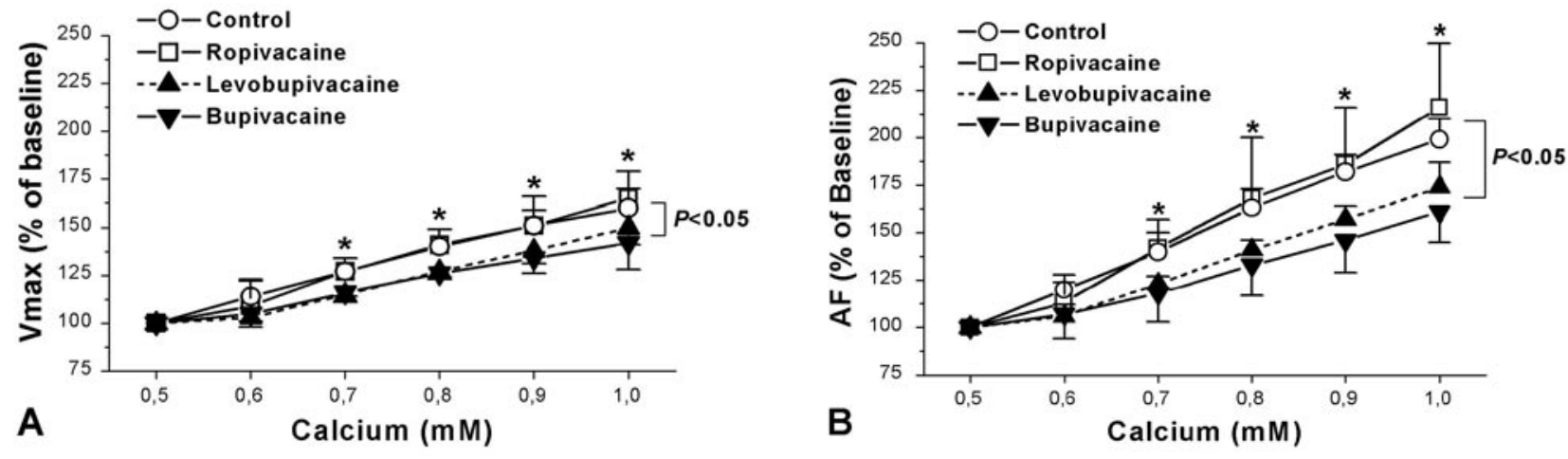

FIGURE 3 Effects of increasing extracellular calcium concentration $\left(\left[\mathrm{Ca}^{2+}\right]_{0}\right)$ on the inotropic responses under low load (panel A) and high load (panel B), in control condition and after $10^{-4} \mathrm{M}$ of ropivacaine, bupivacaine and levobupivacaine. $\mathrm{V}_{\max }=$ maximum unloaded shortening velocity $\mathrm{AF}=$ active isometric force. Data are mean $\%$ of baseline $\pm \mathrm{SD} ; n=6$ in each group. $P$ values refer differences between groups. ${ }^{*} P<0.05$ vs baseline. 


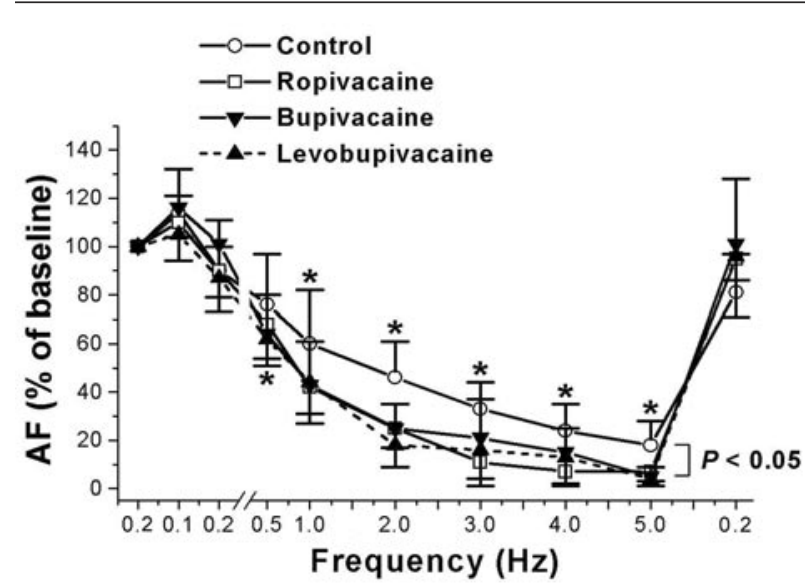

FIGURE 4 Effects of increasing frequency of stimulation (force-frequency relation) on the isometric active force (AF) in control conditions and after $10^{-4} \mathrm{M}$ of ropivacaine, bupivacaine and levobupivacaine at a calcium concentration of $1 \mathrm{mM}$. Data are mean $\%$ of baseline $\pm S D ; n=6$ in each group. $P$ values refer to between groups difference. ${ }^{*} P<$ 0.05 vs baseline.

\section{Discussion}

This study demonstrates in an animal preparation, that LAAs impair myocardial relaxation in isotonic and isometric conditions, and that these effects are more pronounced with bupivacaine and levobupivacaine. Moreover, we confirm that ropivacaine induces less negative inotropic effects than bupivacaine and levobupivacaine under all loading conditions.

This study provides the first in vitro comparison of the effects of LAA on myocardial relaxation. The isolated papillary muscle provides a precise model to assess the mechanical properties of muscle where it is possible to accurately measure (and control) force and length in a multicellular preparation with relatively simple geometry. ${ }^{29}$

We observed that LAAs induce a negative lusitropic effect in isotonic and isometric conditions (Figure 3 ). Because isotonic relaxation strongly depends on calcium reuptake by the $\mathrm{SR},{ }^{23}$ this result suggests an inhibitory effect of LAAs on SR function. That has been suggested recently in ferret ventricular muscle and skeletal muscle..$^{30,31}$ Alteration of the SR by LAAs may occur at the level of the SR $\mathrm{Ca}^{2+}$ release channelryanodine receptor $(\mathrm{RyR})$ or with the calcium reuptake, ${ }^{30,32-34}$ and could be responsible for a decrease in amplitude of contraction and/or increase in the duration of contraction. ${ }^{34}$ We observed an increase in time-to-peak-shortening (isotony) and time-to-peakforce (isometry) that were compatible with alteration of $\mathrm{RyR}$ (increase time to release $\mathrm{Ca}^{2+}$ ). This result is in agreement with the findings of Mio et al. ${ }^{31}$ who described an increase in time-to-peak-light by measuring variation of calcium content with aequorin light intensity measurements. However, we observed that postrest potentiation was not diminished by ropivacaine and bupivacaine, and was enhanced by levobupivacaine. This is not in contradiction with our findings, because rest potentiation is not due to increased $\mathrm{Ca}^{2+}$-current or enhanced $\mathrm{Ca}^{2+}$-entry via $\mathrm{Na}^{+}-\mathrm{Ca}^{2+}$ exchange, and occurs even without changes in SR $\mathrm{Ca}^{2+}$-content. ${ }^{20}$ Chedid et al. also showed that levobupivacaine increased $\mathrm{Ca}^{2+}$ release from SR through $\mathrm{RyR}_{2}$ activation. ${ }^{32}$ It appears that rest potentiation is due to a very slow phase of complete recovery of SR $\mathrm{Ca}^{2+}$-release processes from previous activation. ${ }^{35,36} \mathrm{In}$ rat myocardium, both the increase in SR $\mathrm{Ca}^{2+}$ content and recovery of excitation-contraction coupling from refractoriness may contribute to rest potentiation of $\mathrm{Ca}^{2+}$-release, resulting in pronounced postrest potentiation of the twitch force. ${ }^{12}$

Calcium overload is another phenomenon that may have contributed to LAA-induced SR dysfunction as well as impairment in isometric relaxation. First, calcium overload may have contributed to SR dysfunction because it has been reported that calcium overload impairs SR function, ${ }^{37}$ and because it has been observed that LAAs induce calcium overload and subsequent contracture of both myocardial and skeletal muscle. ${ }^{30,32}$ We observed such a contracture, but were unable to quantify it. Second, and according to the cooperativity concept (i.e., calcium per se modulates myofilament calcium sensitivity), the increase in intracellular calcium concentration probably also resulted in an increase of myofilament calcium sensitivity and subsequent slowing of the rate of myofilament relaxation. ${ }^{26,27}$

Alteration of $\mathrm{Ca}^{2+}$ handling $\left(\mathrm{Ca}^{2+}\right.$ channels and/or alteration of SR) probably takes an important place in the mechanism of LAAs induced myocardial depression. Force-frequency relationship is often used to describe the contractile state and can be altered by inotropic interventions, e.g., by drugs that modified $\left[\mathrm{Na}^{+}\right]_{\mathrm{i}}{ }^{38}$ or that affect $\mathrm{SR} \mathrm{Ca}{ }^{2+}$ uptake and release. ${ }^{21,39}$ Hence, the impairment of FFR, as well as the decrease of inotropic responsiveness to increased calcium concentrations, further reinforced the role of LAAs in the alteration in $\mathrm{Ca}^{2+}$ handling $\left(\mathrm{Ca}^{2+}\right.$ channels and/or alteration of SR) and/or excitation-contraction coupling. ${ }^{39}$

Taken together, these results suggest that in patients with diastolic dysfunction, LAAs may have deleterious effects on diastolic function and have the potential to 
precipitate heart failure. To minimize such risks, and to decrease the incidence of hemodynamic instability in high risk surgical populations (the elderly, patients with ischemic heart disease and/or a history of heart failure), it has been suggested that the dose of LAAs be reduced by combining LAAs with adjuvant drugs such as sufentanil ${ }^{40}$ or to administer LAAs continuously via spinal anesthesia. ${ }^{41}$

The following points must be considered in the assessment of the clinical relevance of our results. First, because this study was conducted in vitro, it examined only intrinsic myocardial contractility. Observed changes in cardiac function in response to ropivacaine, levobupivacaine or bupivacaine administration in vivo will depend on modifications in venous return, afterload, and other compensatory mechanisms. Moreover, it has been shown that LAAs have an effect on conducting tissue. ${ }^{42}$ Second, this study was conducted at $29^{\circ} \mathrm{C}$ and at a low-stimulation frequency. Papillary muscles must be studied at this temperature because it is difficult to maintain stability of mechanical parameters at $37^{\circ} \mathrm{C}$ and at low frequency, because high-stimulation frequency induces core hypoxia. ${ }^{43}$ Lastly, following in vivo administration (for example after unintended intravascular injection) a large proportion of LAAs can bind to $\alpha_{1}$-acid glycoprotein and albumin, ${ }^{44}$ and thus the concentrations of $8 \mu \mathrm{g} \cdot \mathrm{mL}^{-1}$ $\left(3.10^{-5} \mathrm{M}\right.$, bupivacaine) which results in myocardial toxicity, would rarely be achieved clinically. ${ }^{6}$ However, cardiac contractile depression might be observed in clinical practice as it has been observed with blood concentrations of ropivacaine as high as $17.44 \mathrm{mg} \cdot \mathrm{L}^{-1}$ $\left(6.10^{-5} \mathrm{M}\right) .^{45}$ Moreover, it has been shown that tissue concentrations of levobupivacaine in the myocardium could be two to three times greater than the concurrent arterial blood concentrations, ${ }^{46}$ and that displacement of drugs bound to plasma proteins may occur in case of acidosis, ${ }^{47}$ or in the presence of drugs such as $\beta$-blockers and calcium channel antagonists. ${ }^{4}$

In conclusion, LAAs impaired myocardial relaxation and contraction both in isotony and isometry. These negative effects were significantly greater with levobupivacaine compared with bupivacaine and ropivacaine. Modifications in intracellular $\mathrm{Ca}^{2+}$ handling, particularly an impairment of $\mathrm{Ca}^{2+}$ channels and SR function could explain the negative myocardial effects of LAAs.

\section{Acknowledgements}

We thank Dr. Claude Tousignant (St Michael's Hospital, Toronto) for his help in translating the manuscript, Dr. Joelle Goudable, (Department of Biochemistry, CHU Edouard Herriot, Lyon, France) for measurement of ionized calcium and electrolytes, and Florence Arnal, laboratory technician (EA 1896, Claude Bernard University, Lyon), for the management and care of the animals.

\section{References}

1 Owan TE, Hodge DO, Herges RM, Jacobsen SJ, Roger $V L$, Redfield $M M$. Trends in prevalence and outcome of heart failure with preserved ejection fraction. N Engl J Med 2006; 355: 251-9.

2 Groban L, Dolinski SY. Transesophageal echocardiographic evaluation of diastolic function. Chest 2005; 128: 3652-63.

3 Hanouz JL, Massetti M, Guesne G, et al. In vitro effects of desflurane, sevoflurane, isoflurane, and halothane in isolated human right atria. Anesthesiology 2000; 92: 116-24.

4 Gaasch WH, Zile MR. Left ventricular diastolic dysfunction and diastolic heart failure. Annu Rev Med 2004; 55: 373-94.

5 Kass DA, Bronzwaer JG, Paulus WJ. What mechanisms underlie diastolic dysfunction in heart failure? Circ Res 2004; 94: 1533-42.

6 Groban L. Central nervous system and cardiac effects from long-acting amide local anesthetic toxicity in the intact animal model. Reg Anesth Pain Med 2003; 28: 3-11.

7 Vanhoutte F, Vereecke J, Verbeke N, Carmeliet E. Stereoselective effects of the enantiomers of bupivacaine on the electrophysiological properties of the guinea-pig papillary muscle. Br J Pharmacol 1991; 103: 1275-81.

8 Herzig S, Rubnke L, Wulf H. Functional interaction between local anaesthetics and calcium antagonists in guineapig myocardium: 1. Cardiodepressant effects in isolated organs. Br J Anaesth 1994; 73: 357-63.

9 de La Coussaye JE, Bassoul B, Albat B, et al. Experimental evidence in favor of role of intracellular actions of bupivacaine in myocardial depression. Anesth Analg 1992; 74: 698-702.

10 Chang DH, Ladd LA, Copeland S, Iglesias MA, Plummer JL, Mather LE. Direct cardiac effects of intracoronary bupivacaine, levobupivacaine and ropivacaine in the sheep. Br J Pharmacol 2001; 132: 649-58.

11 Royse CF, Royse $A G$. The myocardial and vascular effects of bupivacaine, levobupivacaine, and ropivacaine using pressure volume loops. Anesth Analg 2005; 101: 679-87.

12 Riou B, Lecarpentier $\Upsilon$, Viars $P$. Inotropic effect of ketamine on rat cardiac papillary muscle. Anesthesiology 1989; 71: 116-25.

13 Lyons $G$, Columb M, Wilson RC, Johnson RV. Epidural pain relief in labour: potencies of levobupivacaine and 
racemic bupivacaine. Br J Anaesth 1998; 81: 899-901.

14 Rosenberg PH, Schug SA. Levobupivacaine base and levobupivacaine hydrochloride (Letter). Br J Anaesth 2005; 94: 544.

15 Sia AT, Goy RW, Lim $\Upsilon$, Ocampo CE. A comparison of median effective doses of intrathecal levobupivacaine and ropivacaine for labor analgesia. Anesthesiology 2005; 102: 651-6.

16 Polley LS, Colomb MO, Naughton NN, Wagner DS, van de Ven CJ. Relative analgesic potencies of ropivacaine and bupivacaine for epidural analgesia in labor: implications for therapeutic indexes. Anesthesiology 1999; 90: 944-50.

17 Camorcia M, Capogna G, Columb MO. Minimum local analgesic doses of ropivacaine, levobupivacaine, and bupivacaine for intrathecal labor analgesia. Anesthesiology 2005; 102: 646-50.

18 David JS, Vivien B, Lecarpentier $\Upsilon$, Coriat P, Riou B. Interaction of protamine with alpha- and beta-adrenoceptor stimulations in rat myocardium. Anesthesiology 2001; 95: 1226-33.

19 Prabhu SD, Azimi A, Frosto T. Nitric oxide effects on myocardial function and force-interval relations: regulation of twitch duration. J Mol Cell Cardiol 1999; 31 : 2077-85.

20 Maier LS, Bers DM, Pieske B. Differences in $\mathrm{Ca}^{2+}$ handling and sarcoplasmic reticulum $\mathrm{Ca}^{2+}$-content in isolated rat and rabbit myocardium. J Mol Cell Cardiol 2000; 32: 2249-58.

21 Layland J, Kentish JC. Positive force- and $\left[\mathrm{Ca}^{2+}\right]_{i}$-frequency relationships in rat ventricular trabeculae at physiological frequencies. Am J Physiol 1999; 276(1 Pt 2): H9-18.

22 Hanouz JL, Riou B, Massias L, Lecarpentier Y, Coriat $P$. Interaction of halothane with alpha- and beta-adrenoceptor stimulations in rat myocardium. Anesthesiology 1997; 86: 147-59.

23 Chemla D, Lecarpentier $\Upsilon$, Martin JL, Clerque M, Antonetti A, Hatt PY. Relationship between inotropy and relaxation in rat myocardium. Am J Physiol 1986; 250(6 Pt 2): H1008-16.

24 Lecarpentier $\Upsilon$, Martin JL, Claes V, et al. Real-time kinetics of sarcomere relaxation by laser diffraction. Circ Res 1985; 56: 331-9.

25 Housmans PR, Lee NK, Blinks JR. Active shortening retards the decline of the intracellular calcium transient in mammalian heart muscle. Science 1983; 221: 15961.

26 Hoffman PA, Fuchs F. Evidence for a force-dependent component of calcium binding to cardiac troponin $\mathrm{C}$. Am J Physiol 1986; 253: 541-6.

27 Nwasokwa ON. A model of the time course of myocardial dynamics: use in characterisation of relaxation and evaluation of its indices. Cardiovasc Res 1993; 27: 1510-21.

28 Ludbrook J. Repeated measurements and multiple comparisons in cardiovascular research. Cardiovasc Res 1994; 28: 303-11.

29 Shah AM, Sollott SJ, Lakatta EG. Physio-pharmacological evaluation of myocardial performance: an integrative approach. Cardiovasc Res 1998; 39: 148-54.

30 Zink W, Graf BM, Sinner B, Martin E, Fink RH, Kunst $G$. Differential effects of bupivacaine on intracellular $\mathrm{Ca}^{2+}$ regulation: potential mechanisms of its myotoxicity. Anesthesiology 2002; 97: 710-6.

31 Mio $\Upsilon$, Fukuda N, Kusakari $\Upsilon$, Amaki $\Upsilon$, Tanifuji $\Upsilon$, Kurihara $S$. Comparative effects of bupivacaine and ropivacaine on intracellular calcium transients and tension in ferret ventricular muscle. Anesthesiology 2004; 101: 888-94.

32 Chedid NG, Sudo RT, Aguiar MI, Trachez MM, Masuda MO, Zapata-Sudo G. Regulation of intracellular calcium by bupivacaine isomers in cardiac myocytes from Wistar rats. Anesth Analg 2006; 102: 792-8.

33. Lynch C 3rd. Depression of myocardial contractility in vitro by bupivacaine, etidocaine, and lidocaine. Anesth Analg 1986; 65: 551-9.

34 Komai H, Lokuta AJ. Interaction of bupivacaine and tetracaine with the sarcoplasmic reticulum $\mathrm{Ca} 2+$ release channel of skeletal and cardiac muscles. Anesthesiology 1999; 90: 835-43.

35 Bers DM, Bassani RA, Bassani JW, Baudet S, Hryshko $L V$. Paradoxical twitch potentiation after rest in cardiac muscle: increased fractional release of SR calcium. J Mol Cell Cardiol 1993; 25: 1047-57.

36 Bers DM, Perez-Reyes E. Ca channels in cardiac myocytes: structure and function in Ca influx and intracellular Ca release. Cardiovasc Res 1999; 42: 339-60.

37 Allen DG, Eisner DA, Pirolo JS, Smith GL. The relationship between intracellular calcium and contraction in calcium overloaded ferret papillary muscles. J Physiol (Lond) 1985; 364: 169-82.

38 Mubagwa K, Lin W, Sipido K, Bosteels S, Flameng W. Monensin-induced reversal of positive force-frequency relationship in cardiac muscle: role of intracellular sodium in rest-dependent potentiation of contraction. J Mol Cell Cardiol 1997; 29: 977-89.

39 Antoons G, Mubagwa K, Nevelsteen I, Sipido KR. Mechanisms underlying the frequency dependence of contraction and $\left[\mathrm{Ca}^{2+}\right] \mathrm{i}$ transients in mouse ventricular myocytes. J Physiol 2002; 543 (Pt 3): 889-98.

40 Olofsson C, Nygards EB, Bjertsten AB, Hessling A. Lowdose bupivacaine with sufentanil prevents hypotension after spinal anesthesia for hip repair in elderly patients. Acta Anaesthesiol Scand 2004; 48: 1240-4.

41 Veering BT. Hemodynamic effects of central neural 
blockade in elderly patients. Can J Anesth 2006; 53:

117-21.

42 Aya $A G$, de la Coussaye JE, Robert E, et al. Comparison of the effects of racemic bupivacaine, levobupivacaine, and ropivacaine on ventricular conduction, refractoriness, and wavelength.: an epicardial mapping study. Anesthesiology 2002; 96: 641-50.

43 Paradise NF, Schmitter JL, Surmitis JM. Criteria for adequate oxygenation of isometric kitten papillary muscle. Am J Physiol 1981; 241: H348-53.

44 Mazoit JX, Dalens BJ. Pharmacokinetics of local anaesthetics in infants and children. Clin Pharmacokinet 2004; 43: 17-32.

45 Huet O, Eyrolle LJ, Mazoit JX, Ozier YM. Cardiac arrest after injection of ropivacaine for posterior lumbar plexus blockade. Anesthesiology 2003; 99: 1451-53.

46 Chang DH, Ladd LA, Wilson KA, Gelgor L, Mather $L E$. Tolerability of large-dose intravenous levobupivacaine in sheep. Anesth Analg 2000; 91: 671-9.

47 Denson D, Coyle D, Thompson G, Myers J. Alpha 1-acid glycoprotein and albumin in human serum bupivacaine binding. Clin Pharmacol Ther 1984; 35: 409-15.

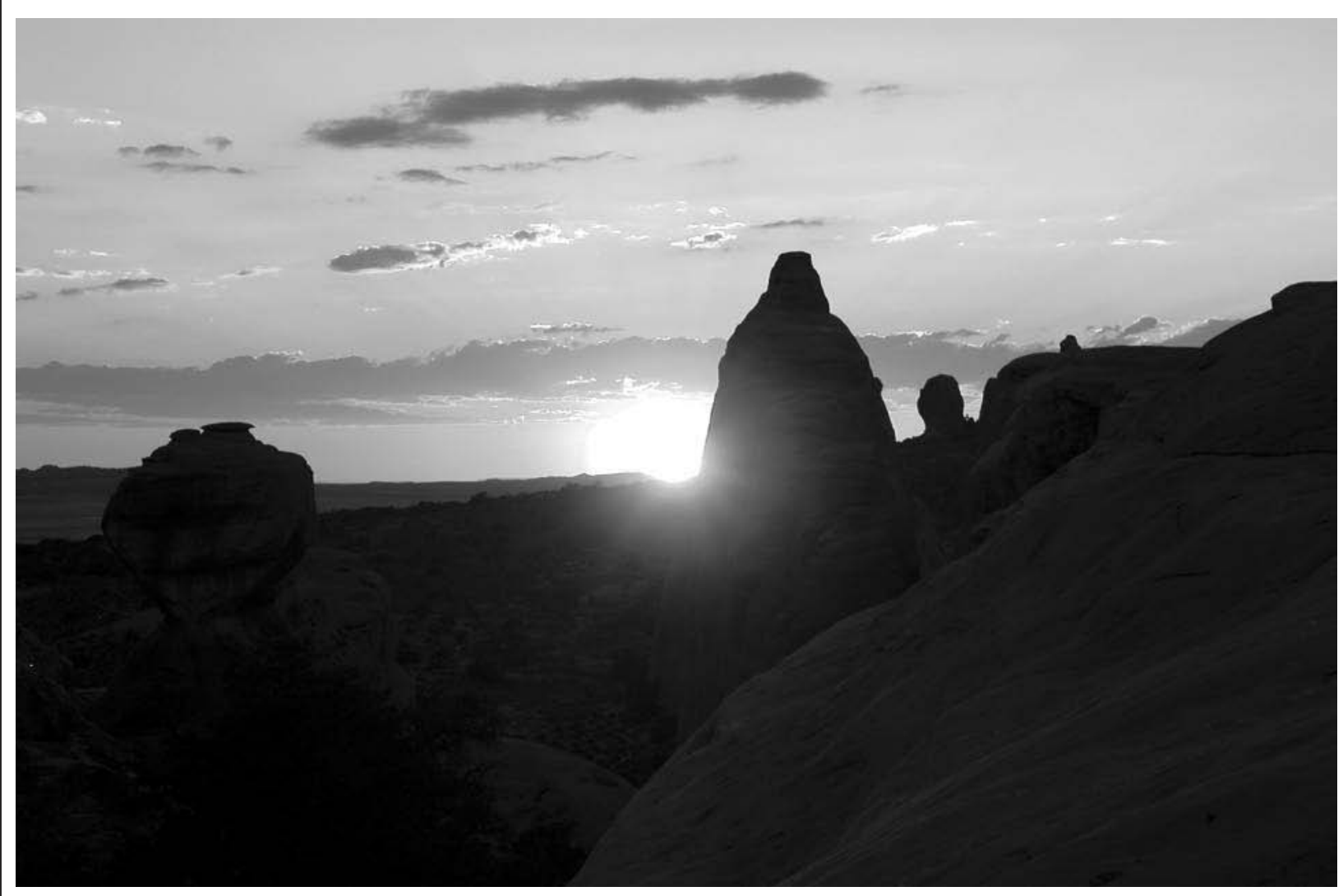

Arches National Park - USA 